\title{
Learning in Facebook: First year tertiary student reflections from 2008 to 2011
}

\author{
Josh McCarthy \\ University of South Australia, Australia
}

\begin{abstract}
This paper reflects on the use of Facebook as an online learning environment for first year design students from 2008 to 2011. Between 2008 and 2010 three student cohorts from the University of Adelaide engaged with their peers through forums hosted by Facebook, submitting work-in-progress imagery and critiquing peers' submissions. In 2011 the study expanded to include national and international collaborators with first year cohorts from Swinburne University in Australia, and Nanyang Technological University in Singapore also participating, allowing students to interact with their global peers. The online forum facilitated increased peer interaction, particularly between local and international students, and improved academic performance as a result of consistent feedback from a range of sources. At the end of 2011 students from the four participating cohorts between 2008 and 2011 were invited to take part in a survey reflecting on and evaluating the learning experiences in Facebook. The results highlighted many positive outcomes regarding the online forum, and have led to the establishment of a series of recommendations for the future use of Facebook as a learning tool, outlined at the conclusion of this paper.
\end{abstract}

\section{Introduction}

This study evaluates the use of Facebook as an online learning environment between 2008 and 2011 within design education at a first year tertiary level. The principle aim of the research was to assess Facebook's effectiveness for improving the first year learning experience by establishing connections, both academic and social, between students, specifically connections between local and international students. Within this aim were two sub-objectives: (a) to increase student participation in academic discussion, be it online or in class; and (b) to improve student performance through peer feedback and critique.

Existing research suggests regular peer-to-peer interaction is responsible for commencing students - local and international - engaging with course material and the learning environment (Krause, Hartley, James, \& McInnis 2005; Sawir, Marginson, Deumert, Nyland, \& Ramia 2008; McCarthy, 2010). Building connections, both academic and social, between peers early in university life is crucial. Web 2.0 technologies, such as social networking sites, have the means to facilitate such actions. In this study, Facebook was used to establish a framework for an evolving, online learning environment that improved the first year experience for all students by promoting social and academic interaction between peers, and utilising the unique learning habits of specific student cohorts and generations.

\section{Peer-assisted learning}

Web 2.0 technologies have changed the learning landscape. As Keen (2007) notes, "for better or worse, Web 2.0 is reshaping our intellectual, political, and commercial landscape." Web 2.0 is participatory and collaborative, reflecting the way Generation-Y engage with technologies and connect with multiple social worlds (McLoughlin \& Lee, 2008). Beyond a tool to connect people, the web has become a medium for participation (Lorenzo, Oblinger, \& Dziuban, 2006). Users are not limited to receiving information - they can comment, collaborate, and create their own content. Moreover, content no longer stands alone; commentary, sharing, and discussion allows anyone interested to actively participate in any forum. In web 2.0 information runs in many directions, is user-created, and is openly shared and accessible. Participation becomes as important as consumption. Rich media forms such as imagery and videos become common, while a vast suite of authoring tools, often free to use, enable individuals to express themselves in different ways.

Online peer-assisted learning has become much more possible with the advent of web 2.0 tools and services (Kirkwood, 2010). These technologies enable participation, communication, personalisation and productivity, and as Bryant (2006) states, these are elements of what it means to be educated in a 
networked age. In the tertiary design education sector it is now possible for learners and teachers to collaborate locally, nationally, and internationally, within a virtual environment. Groups and individuals, learners and teachers, are connected in different ways and are able to contribute to shared projects. Institutions need to recognise this potential and lead the transformation of pedagogy, design of learning tasks, and promotion of learner autonomy and creativity (Leadbeater, 2006). The challenge is to facilitate learning and be open to new media, tools and strategies (McLoughlin \& Lee, 2008). This can be achieved by employing the social software tools, resources, and opportunities that can leverage what our students do naturally - socialise, network and collaborate (Robbie \& Zeeng, 2008).

Web 2.0 technologies incorporate communication features connecting networks of communities for social and informational activities (Robbie \& Zeeng, 2008). The enormous popularity of these continuously evolving and influential tools provides encouragement to explore their potential for teaching and learning in tertiary design education. Available Internet access, flexible working hours, and the attitudes of Generation-Y are drivers of "learning on-demand" (Punie \& Cabrera, 2006) or "'anytime, anywhere" learning (Krause, 2005).

The ubiquitous nature of social networking sites make them ideal for today's students, who consistently spend time using them to access their social life (McLoughlin \& Lee, 2008). Lorenzo, Oblinger, and Dziuban (2006) write:

Web 2.0 tools are changing what it means to be net savvy. Students who have grown up with the internet appear to use information technology and online information seamlessly. Whether through chat, Facebook, or Flickr, they are in touch with friends and acquaintances, evidently trusting the information - and individuals - they encounter online. Friends of friends and those who have similar interests find each other through social networking, whether or not they have met in person.

These tools can be used in combination, and engage people through communication, co-production and sharing (McLoughlin \& Lee, 2008). The innovative use of these tools is becoming core requirements of digital literacies and creativity in the web 2.0 era (Jenkins, Clinton, Purushotma, Robison, \& Weigel, 2007). Web 2.0 tools support independence, higher levels of interaction, access to open communities, and peer-to-peer networking (McLoughlin \& Lee, 2008). This is achieved by facilitating personal choice, collaboration, participation, and creative production. Web 2.0 tools make it easy for learners to engage with their peers, instructors and industry professionals. As Jenkins (2006) writes:

Learning in a networked society involves understanding how networks work and how to deploy them for one's own ends. It involves understanding the social and cultural contexts within which different information emerges... and how to use networks to get one's own work out into the world and in front of a relevant and, with hope, appreciative public. The challenge for educators is to enable self-direction, knowledge building, and learner control by providing options and choice while still supplying the necessary structure and scaffolding. The idea is to have learners exercise greater control over their own learning experience, rather than be constrained by centralised, instructor-controlled learning.

Web 2.0 tools provides for a participatory culture in which there is greater opportunity to initiate, produce and share one's own creations; to engage in peer-to-peer learning; and to become a global citizen (Nikunen, 2011), capable of communicating and working in diverse contexts. With an ever growing number of people reading, writing and commenting on blogs, the way we use the web is shifting in a fundamental way, and Generation-Y is at the forefront of this shift. Instead of being passive consumers of information, more and more internet users are becoming active participants (Tyson, 2010). Users draw upon shared information and connections to learn about acquaintances based on groupings related to common interests, managing a large network of existing relationships and often resurrected past relationships. Educators can utilise this existing behaviour to encourage stronger engagement with course material and interaction within a student cohort. These networks allow users from spatially, temporally, and conceptually distant areas to work together on specific activities within a participatory culture. 


\section{Participatory culture}

A participatory culture is a culture with low barriers to artistic expression and community engagement, strong support for generating and sharing creations, and some type of informal mentorship whereby what is known by the most experienced is passed along to others (Jenkins et al., 2007). According to Willis (2003), in participatory culture:

Young people creatively respond to a plethora of electronic signals and cultural commodities in ways that surprise their makers, finding meanings and identities never meant to be there and defying simple nostrums that bewail the manipulation or passivity of consumers.

Jenkins et al. (2007) state that a participatory culture is one in which there are:

- $\quad$ relatively low barriers to artistic expression and civic engagement;

- $\quad$ strong support for creating and sharing one's creations with others;

- $\quad$ some type of informal mentorship whereby what is known by the most experienced is passed along to novices;

- members believe that their contributions matter; and

- members feel some degree of social connection with one another.

Increasing access to the Internet, via mobile technologies has come to play a fundamental part in the expansion of participatory culture because it increasingly enables people to work collaboratively; generate and circulate news, ideas, and creative works; and connect with others who share comparable goals and interests. There are many potential affordances within these forms of participatory culture, particularly in education. Benefits include opportunities for peer-to-peer learning; the expansion of cultural expression; and the development of skills valued in the modern workplace. Participatory culture shifts the focus of literacy from one of individual expression to community involvement (Jenkins et al., 2007). The new literacies almost all involve social skills developed through collaboration and networking. These skills build on the foundation of traditional literacy, research skills, technical skills, and critical analysis skills taught in the classroom, by providing students with a more informal and relaxed learning environment. Despite these benefits, many tertiary institutions have been slow to react to the emergence of this new learning culture.

If it were possible to define generally the mission of education, it could be said that its fundamental purpose is to ensure that all students benefit from learning in ways that allow them to participate fully in public, community, creative and economic life. (New London Group, 2000).

With the advent of web 2.0 technologies and increased accessibility to the internet, it is no surprise our culture has become more participatory. As Bruns (2008) notes, the implications of the gradual shift from production to produsage are profound, and will affect the very core of our culture, economy, society, and education. According to Bruns, within web 2.0 technologies, the production of ideas takes place in collaborative, participatory environments which breaks down the boundaries between producers and consumers, and instead enables all participants to be users as well as producers of information and knowledge, thus becoming produsers. These new produsers engage not in a traditional form of content production, but are instead involved in produsage - the collaborative and continuous building and extending of existing content in pursuit of further improvement (Bruns, 2008). This concept has the potential to impact on the modern day learning environment, by providing students with an evolving, collaborative, and creative knowledge base, increasingly assessable via mobile technologies.

Not only has contemporary hardware, such as smart phones, increased the individual's ability to upload content to the internet, web 2.0 sites have increased access. Social media websites and tools actively encourage the continual submission of content. Smart phones, such as Apple iPhones or Samsung Galaxy phones, feature site-specific applications that enable users to upload content directly from their phone, without even requiring the use of an internet browser. 
Participatory culture allows a shift in how we approach teaching and learning in the contemporary classroom. The increased availability of the internet within learning environments allows for greater access to information. As Leander (2002) notes, it is no longer necessary for relevant knowledge to be contained in some combination of the teacher and textbooks; today, knowledge can be more decentralized and made available for all learners to access. This mobilises the teacher to facilitate efficient and effective means of accessing, interpreting, and making use of that knowledge.

While it matters what the technologies and tools that are available, what is more important is how a generation chooses to use and interact with such tools. As Jenkins (2006) notes, interactivity is a property of the technology, while participation is a property of culture. Participatory culture is emerging as the culture absorbs and responds to the explosion of new media technologies that make it possible for average consumers to archive, annotate, appropriate and recirculate media content in powerful new ways (Jenkins, 2006).

Participatory culture has also been referred to as affinity spaces (Gee, 2004). According to Gee, these spaces offer powerful opportunities for learning, because they are sustained by common endeavours that bridge differences in age, race, gender, and educational level. Affinity spaces can also enable people to participate in various ways according to their skills and interests, because they depend on peer-to-peer teaching with each participant constantly motivated to acquire new knowledge or refine their existing skills. Gee notes that affinity spaces are distinct from formal educational systems in several ways. While formal education is often conservative, the informal learning within popular culture is often experimental. While formal education is static, the informal learning within popular culture is innovative (Gee, 2004). The structures that sustain informal learning are more provisional and open to change, while those supporting formal education are more institutional. Bearing in mind the unique approaches to learning of Generation-Y students (Krause et al., 2005; McCarthy, 2010), the increasing accessibility of the internet, and the affordances of web 2.0 technologies, participatory culture offers many benefits to the evolving landscape of tertiary education.

\section{Web 2.0 pedagogy}

Based on the principles of peer-assisted learning and participatory culture, along with the benefits of web 2.0 technologies, a new pedagogy emerges. This new pedagogy is not just a matter of providing learners with the technologies they are likely to use day to day. These technologies are subject to change. It is about providing learners with a platform to share, converse, discuss and critique (McLoughlin \& Lee, 2008). Principles supporting effective, innovative pedagogy will change depending on the course or professional discipline in which students are enrolled, however McLoughlin and Lee (2008, p. 12) note they are likely to include:

- Digital competencies that focus on creativity and performance.

- Strategies for meta-learning, including learner-designed learning.

- Inductive and creative modes of reasoning and problem solving.

- Learner-driven content creation and collaborative knowledge building.

- Peer-to-peer learning and contribution to communities of learning (through social tagging, collaborative editing, and peer review).

Technological resources provide opportunities for a range of interactions, communicative exchanges, and sharing, but it is not possible to base an entire sequence of learning episodes solely on tools (McLoughlin \& Lee, 2008). Pedagogical frameworks, informed by learner-centred principles, and sensitive to the learning context, need to be considered. In the classroom, this means that before attempting to gain the benefits of social software tools, teachers need to identify pedagogical outcomes and ensure that technology integration is aligned to assessment. The drive to connect and participate within the community, and the desire to feel part of a group committed to learning, is shaping the pedagogy, and web 2.0 technologies afford such desires. As Kirkwood (2010) notes, "the web is no longer only or even primarily about disseminating and linking information; it is about linking and empowering people." This is supported by Staley (2009), who believes web 2.0 technologies represent as important a historical phenomenon as the birth of bureaucracy, in that they have created a participatory turn in our culture. Rather than being a passing fad, "Web 2.0 is an evolution in the social architecture and functionality of the web." 


\section{Choosing Facebook as the learning environment}

Social network sites (SNSs) allow individuals to present themselves, articulate their social networks, and establish or maintain connections with others (McCarthy, 2012). SNSs are amongst the most visited sites on the internet, with Generation-Y at the forefront of the popularity surge around the world. Facebook, the world's most popular social networking site with over 1 billion monthly active users at the time of this writing (www.facebook.com), promotes the development of "preliminary" relationships between first year students, particularly between students of different cultures, as it negates key pitfalls such as language barriers and social inhibitions. It allows users to set up a personal page, post information and interact within a range of different social networks.

Facebook was chosen as the host site for this research because of the uniform strength of its features as compared to other popular SNSs such as MySpace and Friendster, the image-sharing site Flickr, and the open-source learning management system Moodle (McCarthy, 2010). It was also expected that students would be more inclined to participate in the learning environment and subsequent assessment if it was hosted by a site they already intended to visit repeatedly (McCarthy, 2009). Facebook is easily accessible - available to users for free, and accessible from mobile forms of technologies, such as smart phones and tablet computers. Its interface is intuitive and user friendly. Many students are already using Facebook extensively for their own purposes outside the classroom (and often in the classroom unrelated to their studies) - it is already deeply integrated into their day-to-day practices. Educators are starting to see the potential benefits of sites such as Facebook in tertiary curriculum, as Stutzman (2007) writes:

There is something essentially placeful about online social networks; as I log in, I am engaged by a cross-section of my social relationships. In an instant information is revealed, opportunities are discovered, and a website becomes a social nexus - from which I can derive a sense of gratification, meaning and identity.

Educators have widely acknowledged the value of community building and social interaction with and among students, in both face-to-face and online classes (Duffy, 2011; Palloff \& Pratt, 2007). With the emergence of SNSs such as Facebook, learners have developed a social world that is parallel to and often interlinked with their everyday work and study activities. Many researchers see web 2.0 technologies in general as having the potential to transform e-learning and traditional teaching methods (Duffy, 2011), while Facebook, in particular, can facilitate the development of communities of practice (Wenger, 1998) and communities of interest (Fischer, 2001). The primary benefits of Facebook as a learning tool arise from its ability to enable students to share information, knowledge, and artefacts within a community (McCarthy, 2012). Facebook offers possibilities to help transform the delivery of instruction and information in the classroom, by facilitating participatory and collaborative student action. The use of Facebook's comment feature stands as one of the primary educational benefits of the site (Richardson, 2006; Duffy, 2011), as the posting of online comments by students encourages them to engage with positions differing from their own, while the ability to create content for and present to a potentially global audience also creates more interest in the course material, within the student cohort.

Despite the many associated positives, it is important that new technologies are integrated into learning and teaching only when driven by pedagogy, rather than technology for technology's sake. As Cluett (2010) notes, launching a university presence on a publicly available sites creates significant challenges and risks. Cyber-bullying and privacy, perhaps the most prevalent risks, can be dealt with using Facebook's administrative rules and toolsets. Page administrators (i.e., course coordinators) are granted simple and effective options for blocking and reporting users who mistreat others or who post offensive content. Similarly Facebook's terms and conditions, as well as the University's IT policy, ensure any such mistreatment is dealt with appropriately. Individual users (i.e., students and staff members) have access to extended privacy parameters that allow them to share and block any information they choose. As has always been the case, it is the responsibility of the course coordinator to ensure that all students are informed of the terms and conditions that govern the classroom, be it physical or virtual, and that students are expected to engage with the course material and interact with their peers within these rules.

At the commencement of this research, Facebook and Flickr were viewed as the two key candidates to act as host site. The decision to choose Facebook was not made lightly, and ultimately came down to three 
factors: (a) Facebook's ability to host unlimited content (as opposed to Flickr's 300 megabytes of images and only two videos per month for free accounts); (b) a perception that Facebook's interface and framework provided a stronger, more complete learning environment, with greater potential for social interaction as well as academic interaction; and (c) an expectation that students would be more willing to spend time on Facebook rather than on Flickr, and as such engage with the course material and interact with their peers more thoroughly. Since choosing Facebook as the host site for the online learning environment in 2008, it has been successfully implemented in a series of other case studies (McCarthy 2012; Irwin, Ball, Desbrow, \& Leveritt, 2012; Rambe, 2012).

\section{Case studies from 2008 to 2010}

Facebook was incorporated into the first year design course Imaging Our World in the School of Architecture, Landscape Architecture and Urban Design at The University of Adelaide in 2008. One hundred students, including 23 international students, took part in the study. Every two weeks, students were required to submit images to an online gallery in Facebook, and to provide critiques on peers' submissions (McCarthy, 2009). The gallery topics were broad in nature, and open to the students' own interpretations, allowing for a wide range of images in each: this produced a concurrently wide range of discussions. The 2008 experience showed that the virtual classroom hosted by Facebook provided a platform for students to generate preliminary academic and social interactions with peers in first year university, while meeting the diverse learning needs and attitudes of Generation-Y (McCarthy, 2009). These relationships however often stayed embryonic in nature, due to a lack of connection between the real and virtual classrooms.

The learning experience was adapted in 2009 to help forge more meaningful connections between peers. It is crucial to remember that an online connection is only one factor in forming a meaningful relationship, and that physical interaction with peers is essential for developing the student experience (McCarthy, 2010). This factor became the catalyst for blending the physical and online learning environments. Discussions, generated within the online environment, were then taken into the physical classroom and further developed under the direction of the teacher. In the pilot study in 2008 it became evident that the online tasks were most beneficial during the early weeks of semester with participation waning during the latter stages of the semester. For this reason the Facebook assessment in 2009 was compressed into an intensive 6-week program to capitalise on the initial enthusiasm and interaction of students. The 2009 experience outlined a blended learning environment helped transform emergent online connections into meaningful relationships by supporting virtual communication with face-to-face interaction in the classroom (McCarthy, 2010).

In 2010 it was hoped to transform the project into a national and international design studio where first year students around Australia and overseas could come together, share design ideas, comment on and critique peers' work, and learn about design around the world. Finding partners for 2010 proved to be difficult, and instead the triangulated collaboration was put off until the first half of 2011 when Swinburne University in Melbourne, Australia, and Nanyang Technological University in Singapore, were able to take part. As a result the principle aim of the 2010 study was to replicate the success of the blended learning environment from 2009. The 2010 student group in Imaging Our World did however provide a new challenge in that, due to the course's popularity, the cohort was made up of students from no less than eight different programs within the University of Adelaide. This new diversity in academic backgrounds within the cohort placed further importance on the learning environment in Facebook and the subsequent transferral of discussions and critiques into the physical classroom. Due to the varied student cohort it was decided that a stronger focus would be placed on work-in-progress galleries within Facebook, allowing students to gain feedback on major projects throughout the semester. The subsequent shift in focus from stand-alone content galleries to work-in-progressgalleries in 2010 revealed that the virtual environment in Facebook enabled students to produce strong academic results, by submitting preliminary design work throughout the semester and receiving constant feedback from a range of sources.

\section{The 2011 international first year design studio}

In 2011, the Facebook learning environment in Imaging Our World was transformed into a national and international design studio, with students from The University of Adelaide (enrolled in the course 
Imaging Our World); Swinburne University in Melbourne (enrolled in the course Photography in Communication Design); and Nanyang Technological University in Singapore (enrolled in the course Stop Motion Workshop), taking part. Swinburne University was chosen as a partner due to its use of Flickr as an online learning tool from 2007 to 2010 (Robbie \& Zeeng, 2008), and its strong theoretical focus on photography as a communicative tool within the Bachelor of Design (Communication Design) program. Nanyang Technological University was chosen as a partner due to its previous use of Facebook as an e-learning tool for peer critiques, and its focus on photography in animation within the Bachelor of Fine Arts in Digital Animation program. It was expected that these two different approaches to using photography in the design world, would complement the focus on photography in graphic design within Imaging Our World, and provide all participating students with the opportunity to expand their knowledge of photographic theory, techniques and principles. It was also expected that linking these three student cohorts would provide students with the opportunity to learn about different areas of design, to learn about design outside of their immediate location, and to connect them with their national and global peers.

The 2011 learning experiment utilised two different host sites. Due to its success in previous years (Robbie \& Zeeng, 2008) the Swinburne University cohort continued to use Flickr as a host site for their online learning environment. The cohorts from The University of Adelaide and Nanyang Technological University used Facebook as host site, again based on the success of previous years' studies. Another change in 2011was switching from the group tool to the page tool for creating the learning environment within Facebook. This change was a result of Facebook shifting the capabilities and functionality of the group tool. Assessment related to the online learning environments varied between the three courses, however emphasis was placed on intra-institutional and cross-institutional peer critiques.

The 2011 case study made it clear that it would be best if all student cohorts used the same host site either Facebook or Flickr - in future collaborations. While those Swinburne students who did participate in the Facebook galleries benefitted from doing so, there wasn't interaction from the whole group. Despite this, participation from Adelaide students in Flickr was consistently strong over the semester. Interaction between Adelaide and Singapore was also robust, particularly later in the semester, due to the sharing of the same host site, and the enthusiasm of the students. As one student from Adelaide noted:

The best part of this course [Imaging Our World] was the freedom to explore new areas of design, and the ability to see students working in different areas of design. The Facebook page provided a platform for us to explore design and then get feedback from our peers. I found it rewarding to see student work from Singapore and compare it to the designs we were creating here.

Adelaide students benefitted from seeing national and international work, including different forms of photography through the NTU students; and receiving feedback from a much wider range of peers than in previous years.

The continued focus on work-in-progress galleries, rather than stand-alone galleries, in Facebook, supported the cohort's overall academic performance, with students able to receive continual feedback related to major projects. This was again of particular benefit to students from a non-design background, still coming to terms with basic design theory and knowledge. Face-to-face interaction between local and international students continued to improve in 2011, with more time spent in the lectures devoted to the national and international collaborations, in-house online discussions, and peer critiques. There was also a significant increase in social interaction within the cohort with students taking advantage of the popularity of the Imaging Our World Facebook page by posting upcoming events, such as student art exhibitions and music concerts, to the wall in Facebook, inviting all to attend. This was reflected in the dramatic increase in social interaction between peers, specifically cross-cultural social connections, as discussed in the next section of this paper.

\section{Developing social and academic relationships}

Data was collected during end-of-semester surveys from 2008 to 2011 (McCarthy 2009; McCarthy, 2010). This section maps the mean responses from local and international students in regards to the academic and social affordances of the online learning environment in Facebook. Figure 1 shows the 
development of same-culture academic relationships within the four student cohorts. Responses from students were consistently positive, with a significant increase in the development of academic relationships between local students from 2008 to 2009. This increase occurred simultaneously with the transformation from the two separate learning environments into the blended learning environment in 2009.

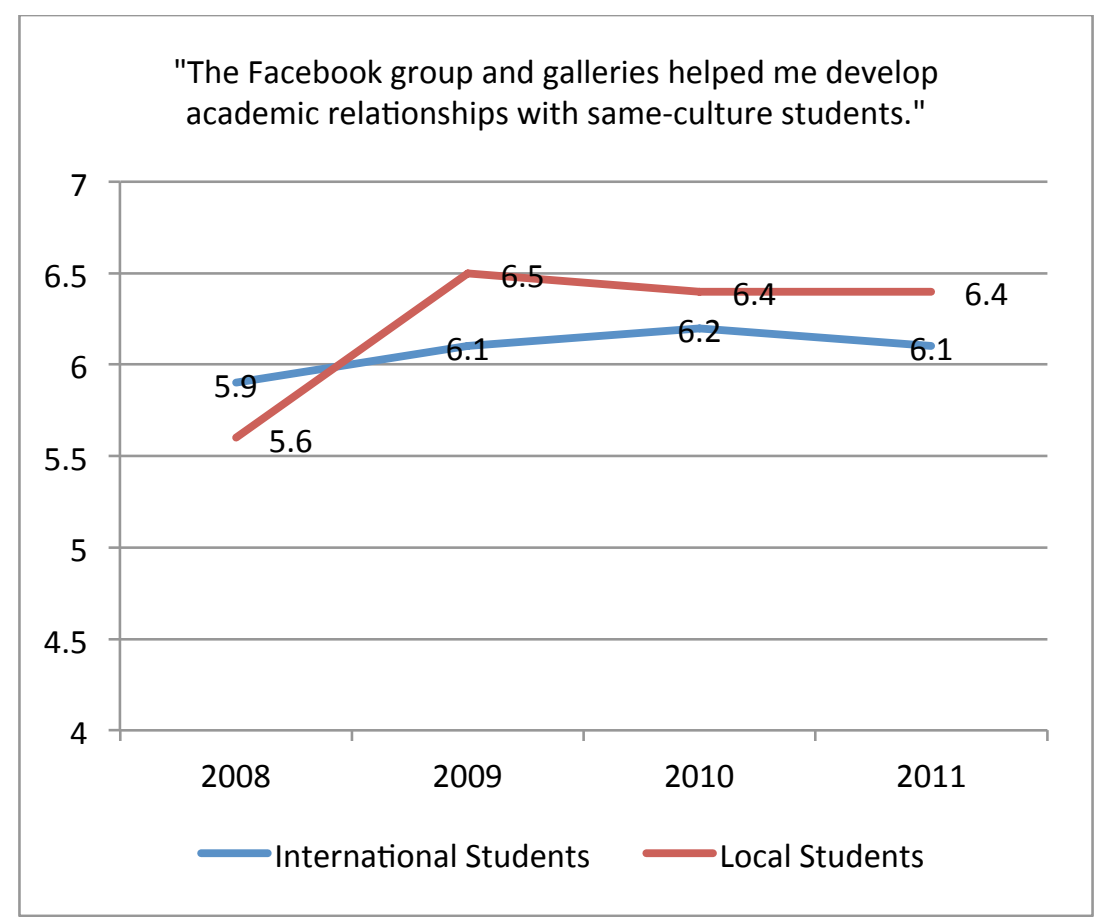

Figure 1. This graph shows the mean responses from international and local students within Imaging Our World from 2008 to 2011, in regards to the statement "the Facebook group and galleries helped me develop academic relationships with same-culture students." The survey used a 7-point Likert scale from 1 (strongly disagree), to 4 (undecided), to 7 (strongly agree).

Figure 2 shows the development of different-culture academic relationships within the four student cohorts. There were consistent increases in the development of cross-cultural academic relationships over the four years, in line with the blending of real and virtual environments, and the increased focus on work-in-progress submissions within Facebook. Figure 3 shows the development of same-culture social relationships over the four years. There was no significant increase in the development of social relationships within similar cultural groups. The online learning environment in Facebook proved to be more successful at developing cross-cultural social relationships as outlined in Figure 4. This development was most successful in 2011 and coincided with the incorporation of national and international collaborators. In $201189 \%$ of all students in the Imaging Our World cohort indicated that the Facebook page and content galleries helped develop social relationships with peers from different cultures, as compared to $79 \%$ in $2010,77 \%$ in 2009 , and $82 \%$ in 2008 .

Figures 5 and 6 relate to general interaction between peers. Figure 5 shows the increase of interaction between peers during the four year study. General interaction increased significantly in 2009 with the blending of the real and virtual learning environments, and was maintained in the following years. Figure 6 maps academic discussion that benefitted students' studies within the course. The responses from students were consistently high over the four years, with gradual improvement year to year. The mean responses from international students are of particular note when considering the findings of the national studies reported by Krause et al. (2005) and Sawir et al (2008). The online learning environment provided students with the opportunity to improve their understanding of design, and consequently their performance, through academic discussions with peers. Given the growing number of international students studying in Australia (www.studiesinaustralia.com), and the importance of the international student market to the Australian economy, collaborative learning tools, such as the Facebook group in Imaging Our World, should be considered for adoption within curriculum more readily. The highest 
responses came in 2010 and 2011 with the shift in focus from stand-alone content galleries to work-inprogress galleries, and the introduction of national and international collaborators. This highlights the importance of providing students with opportunities to converse with peers in an academic forum on national and international scales.

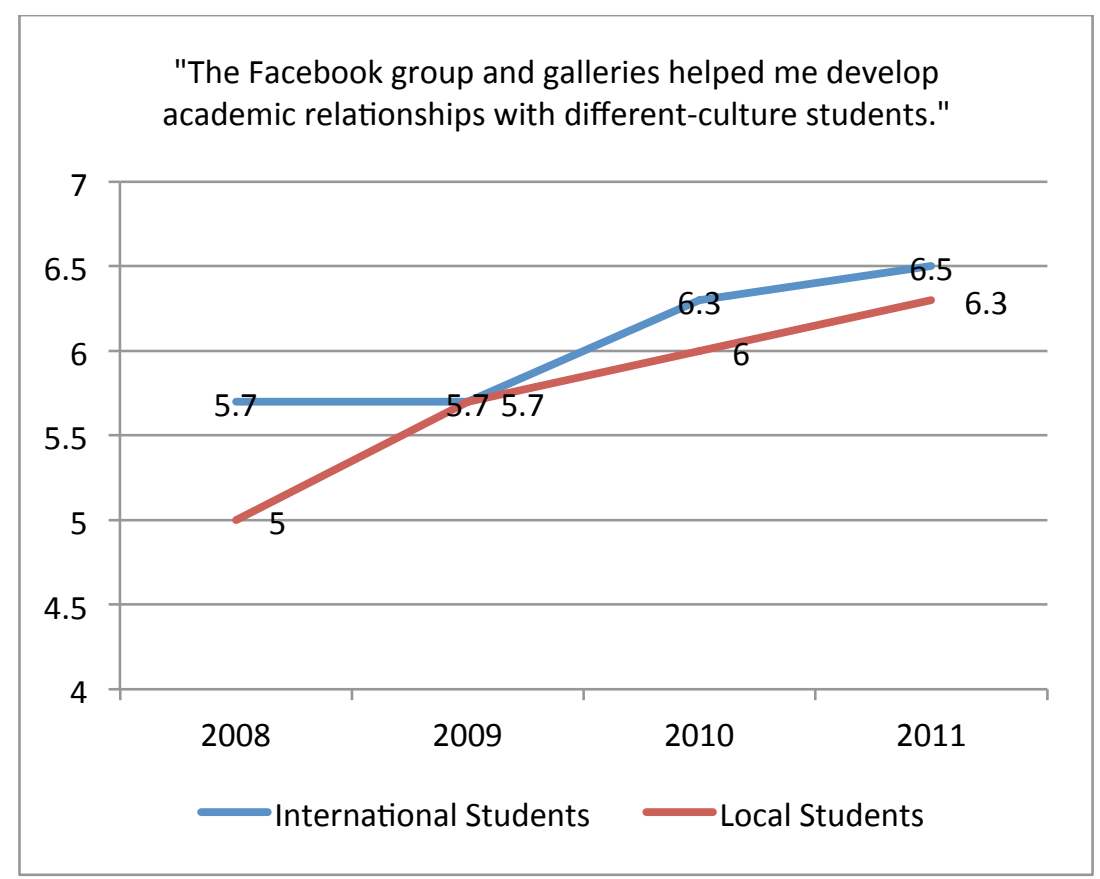

Figure 2. This graph shows the mean responses from international and local students, in regards to the statement "the Facebook group and galleries helped me develop academic relationships with differentculture students."

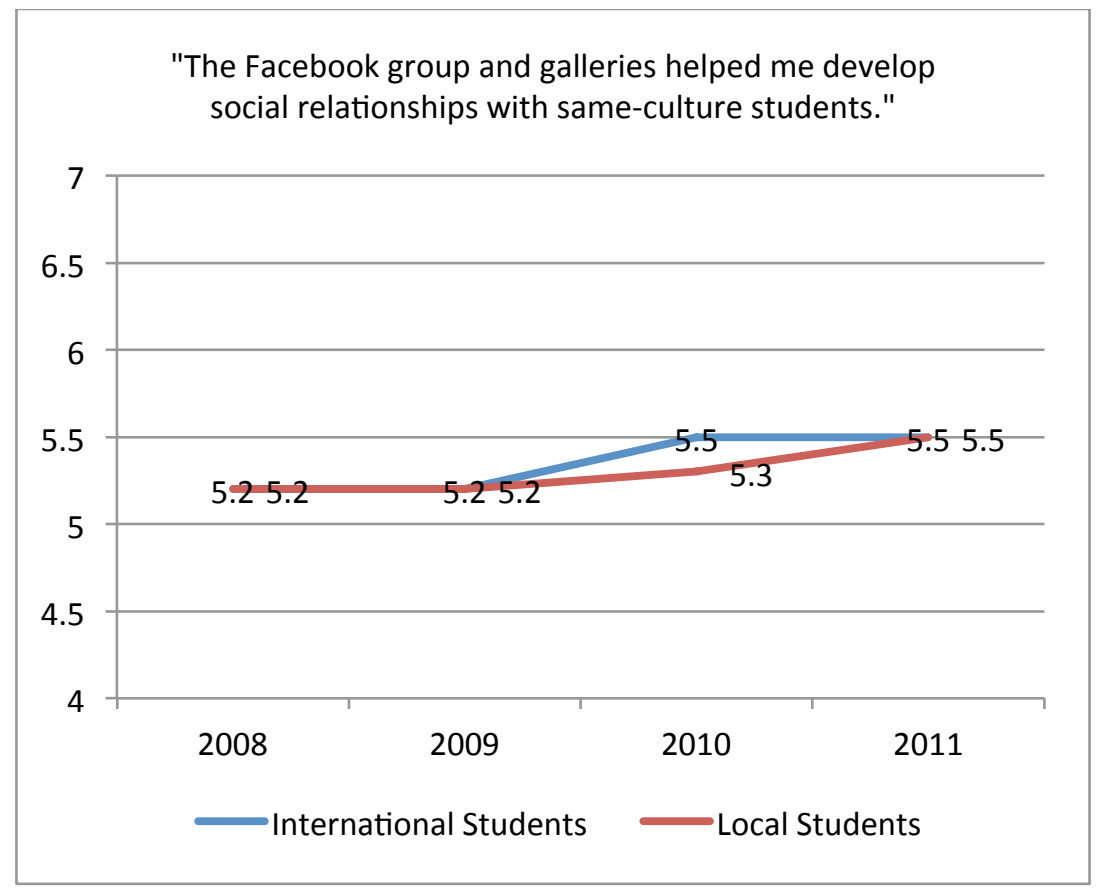

Figure 3. This graph shows the mean responses from international and local students, in regards to the statement "the Facebook group and galleries helped me develop social relationships with same-culture students." 


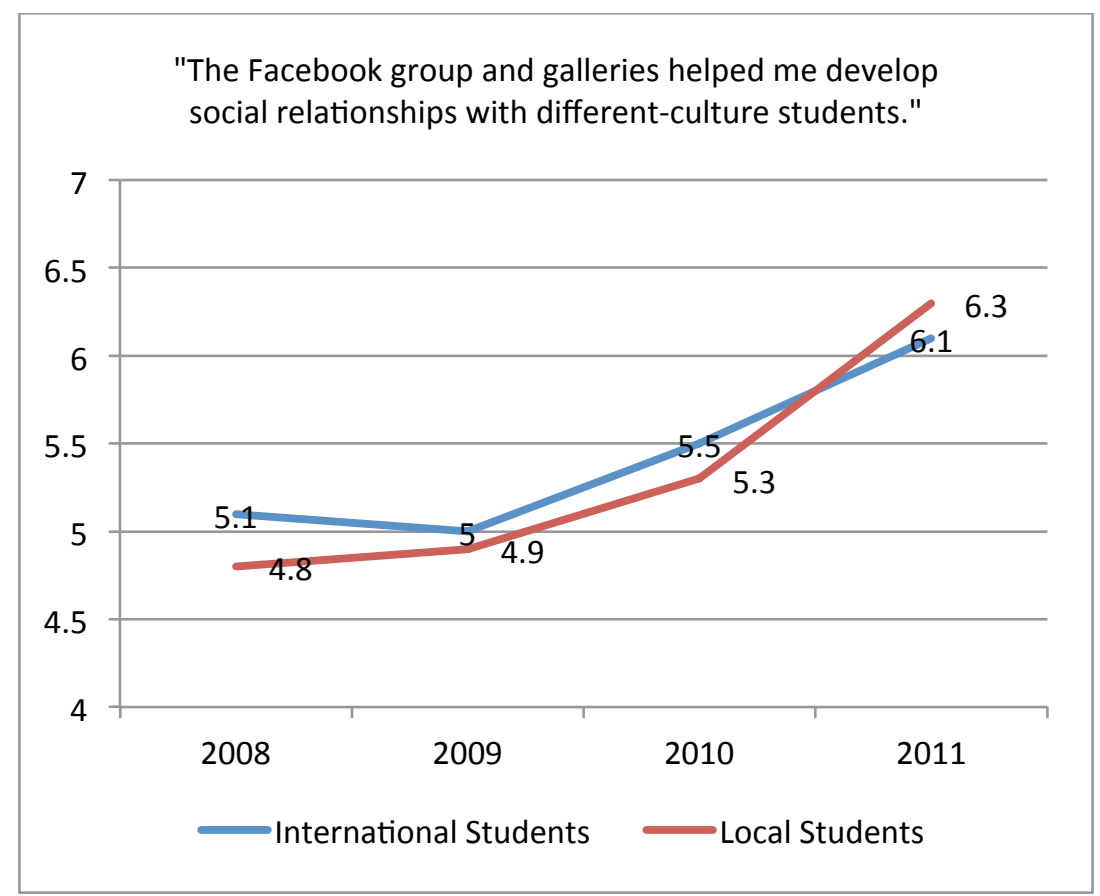

Figure 4. This graph shows the mean responses from international and local students, in regards to the statement "the Facebook group and galleries helped me develop social relationships with different-culture students."

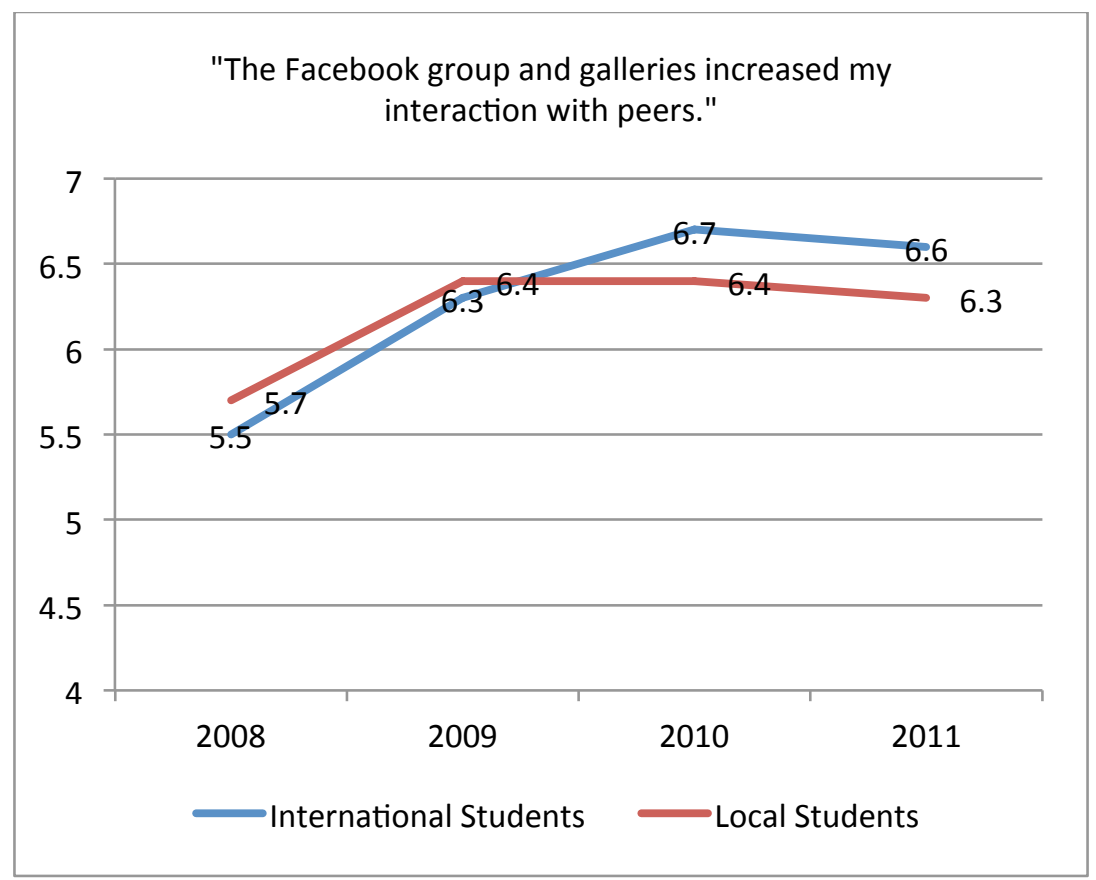

Figure 5. This graph shows the mean responses from international and local students, in regards to the statement "the Facebook group and galleries increased my interaction with peers." 


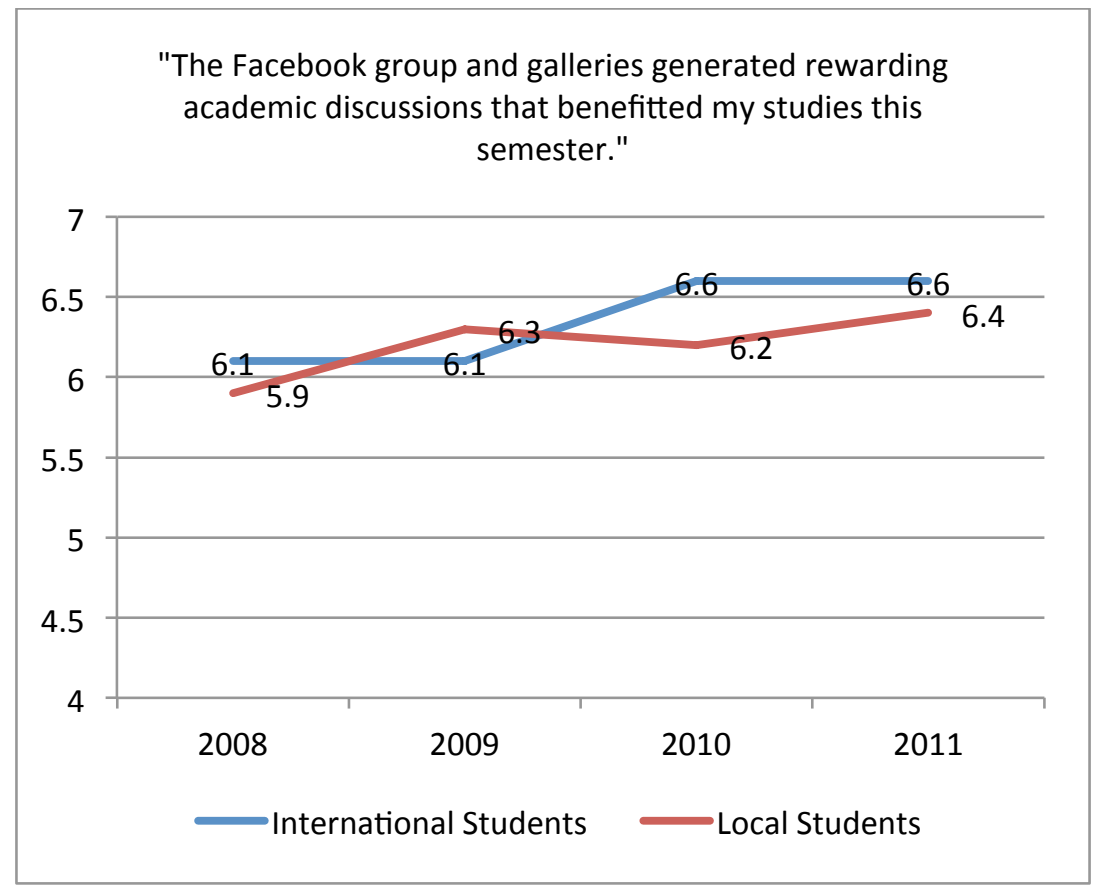

Figure 6. This graph shows the mean responses from international and local students, in regards to the statement "the Facebook group and galleries generated rewarding academic discusssions that benefitted my studies this semester."

\section{Student reflection surveys in 2011}

In 2011, all students who were enrolled in the course Imaging Our World between 2008 and 2011 were invited to participate in another survey reflecting on and evaluating the learning experiences in Facebook. Students who were enrolled in the course from 2008 to 2010 participated in a survey in July 2011, while students who were enrolled in the course in semester one 2011 participated in a survey in November 2011. The survey was distributed via email and participants were asked to print it out and submit it to a marked box in the school to ensure student anonymity was retained. The principle aims of the survey were (a) to establish students' perceptions as to the advantages and disadvantages of the online learning environment in Facebook; and (b) to compare the learning experiences using Facebook in Imaging Our World to other courses in future years of study.

The survey included three broad types of measures. Firstly, information about demographic and other descriptive variables, including gender, age bracket, ethnicity, and the year the student was enrolled in Imaging Our World, was collated. Secondly, open-ended questions collected students' attitudes regarding the advantages and disadvantages of the online learning environment in Facebook; how the learning experiences in Imaging Our World compared to other courses in their studies; and whether they had used Facebook as an online learning tool again. Thirdly, Likert-scale statements collected information regarding academic and social relationships formed with local and international peers during the course.

\section{Student reflections on the learning environment in Facebook}

In total 116 students from the four cohorts took part in the two surveys, including 52 international students. Table 1 outlines the breakdown of student demographics from the survey respondents. 
Table 1

Imaging Our World experiences and reflections survey 2011; Breakdown of student demographics.

\begin{tabular}{llll}
\hline Demographic & $\begin{array}{l}\text { Number of } \\
\text { students (Local) }\end{array}$ & $\begin{array}{l}\text { Number of students } \\
\text { (International) }\end{array}$ & $\begin{array}{l}\text { Number of students } \\
\text { (All) }\end{array}$ \\
\hline Gender: & 20 & 22 & 42 \\
Male & 44 & 30 & 74 \\
Female & & & \\
Age: & 50 & 33 & 83 \\
$17-20$ & 12 & 18 & 30 \\
$21-25$ & 2 & 1 & 3 \\
$26+$ & & & \\
Ethnicity: & 64 & 0 & 64 \\
Local & 0 & 52 & 52 \\
International & & & 22 \\
Imaging Our World Cohort: & 8 & 14 & 32 \\
2008 & 16 & 16 & 35 \\
2009 & 22 & 13 & 27 \\
2010 & 18 & 9 & \\
2011 & & & \\
\hline
\end{tabular}

The participating students listed many advantages of the online learning environment in Facebook, related to both social and academic outcomes:

Making friends. (International student, 2009 cohort)

Finding friends in the course through similar hobbies. (International student, 2010 cohort)

Getting feedback - so good and so easy! (International student, 2010 cohort)

Accessibility was a big plus. You could do a lot of work from home, I even submitted work from my phone on the bus. (Local student, 2010 cohort)

Talking with local students. It was so helpful to have this tool. It helped develop my English skills and developed my design skills through the feedback and comments. (International student, 2010 cohort)

Getting to know everyone in the course at the start of semester. I didn't know anyone coming in but within a week or two knew heaps of people through the Facebook group and in class. (Local student, 2008 cohort)

Definitely learning about new design. [Course coordinator] and students would post links to sites, videos and articles that were relevant to the course. Just a really good and easy resource to use. (Local student, 2010 cohort)

Most students reflected on the positives of the online learning environment in Facebook, however some did note disadvantages of using the site in Imaging Our World:

I guess privacy might have been an issue for some people, but if you set it up right [your personal Facebook page] then it shouldn't be. (Local student, 2009 cohort)

I didn't like Facebook to begin with and found the whole concept a bit hard to get into, but when we started getting good feedback on work it started to make a lot more sense. (Local student, 2009 cohort) 
Yeah, not a huge fan of Facebook or virtual communication in general, but it was good to broaden my horizons a bit. The feedback was good. Don't use Facebook anymore but thought it was a pretty good way to get everyone involved in the course, as it is popular with most people. (Local student, 2008 cohort)

It dragged out a bit at the end of semester particularly with major assignments on at the same time with other courses. I had a friend who did the course the year after and said it was only on in the first half of the semester. I would definitely say that's an improvement. (Local student, 2008 cohort)

When asked to compare the learning experiences in Imaging Our World to other courses they had completed, students provided interesting insight. There was a strong focus on the social qualities of the course:

There seemed to a much stronger focus on the social experience in Imaging Our World which it made it so much more relaxing and enjoyable. Classes were fun and it was cool to use Facebook. (Local student, 2010 cohort)

The focus in Imaging Our World was on forming connections with our peers. It was really good having this course in first year - sets you up with a group of friends. We don't have anything like this in third year. (Local student, 2009 cohort)

As well as developing an understanding of design, through furthering their knowledge base, submitting and critiquing work-in-progress, and receiving helpful feedback:

IOW was great for discussing design. The assignments were open and let us explore different areas of design, and it was super easy to get feedback on Facebook. Discussion boards on MyUni aren't as good because they aren't as easy to read through and post comments to. (Local student, 2009 cohort)

It was fun! Everyone got along and the classes were great talking about photography and design. It is more serious now, more about the work and less about the student group. (International student, 2010 cohort)

Feedback. In IOW you could get so much help and comments on your work. Just throw up a pic on Facebook and people would comment on it. (Local student, 2011 cohort)

Students were also asked whether they had used Facebook as an online learning environment since Imaging Our World in first year. While no students said that they had in an official capacity within a course, almost all students used the site in less formal ways:

I use Facebook when we have group projects. It's great because it's easy to access and everyone is familiar [with it.] (International student, 2009 cohort)

Unfortunately not officially for any courses. We do use it between ourselves however to share work-in-progress and discuss design ideas. (Local student, 2008 cohort)

Yes, a group of us set up a page for our core course this year because we don't like MyUni. It's so much easier to chat, post work and start discussions. It is much more intuitive. (Local student, 2011 cohort)

Yes, well sort of...I use Facebook to stay in touch with friends from first year because I've gone into a different program now. It's great to hear about what's happening in Design Studies and see what my friends are designing. (Local student, 2009 cohort)

I wish! We use Showoff [Moodle] which is not nearly as good. Everybody has a Facebook [page] and everyone is always using it. It just makes sense to use it for uni as well. I guess particularly for design. (Local student, 2010 cohort) 
Not for a whole course, but I use it to share ideas with friends and [to] discuss design. [It is] a good tool for discussions about design and concepts. (International student, 2010 cohort)

Yes, my friends and I always use Facebook at the start of semester to share work and ideas. We just set up [a] group and it's so easy to post work and have discussions. (International student, 2010 cohort)

Lastly students were asked to comment on the development of academic and social relationships with both local and international students through using Facebook as an online learning tool. Mean responses from the four Likert-scale questions were consistent with those produced in the post-semester surveys between 2008 and 2011. The student responses are outlined in Table 2.

Table 2

Imaging Our World experiences and reflections survey 2011; Likert-scale topics.

\begin{tabular}{|c|c|c|c|c|c|c|}
\hline $\begin{array}{l}\text { Topic (116 respondents took } \\
\text { part in the two surveys) }\end{array}$ & $\begin{array}{l}\text { Mean } \\
\text { (Local) }\end{array}$ & $\begin{array}{l}\% \text { Broad } \\
\text { Agreement }\end{array}$ & $\begin{array}{l}\text { Mean } \\
\text { (Int.) }\end{array}$ & $\begin{array}{l}\% \text { Broad } \\
\text { Agreement }\end{array}$ & $\begin{array}{l}\text { Mean } \\
\text { (All) }\end{array}$ & $\begin{array}{l}\% \text { Broad } \\
\text { Agreement }\end{array}$ \\
\hline $\begin{array}{l}\text { "Upon reflection, the online } \\
\text { learning environment in } \\
\text { Facebook helped develop } \\
\text { academic relationships with } \\
\text { same-culture students." }\end{array}$ & 6.1 & $86 \%$ & 6.1 & $90 \%$ & 6.1 & $88 \%$ \\
\hline $\begin{array}{l}\text { "Upon reflection, the online } \\
\text { learning environment in } \\
\text { Facebook helped develop social } \\
\text { relationships with same-culture } \\
\text { students." }\end{array}$ & 5.8 & $85 \%$ & 5.7 & $80 \%$ & 5.7 & $82 \%$ \\
\hline $\begin{array}{l}\text { "Upon reflection, the online } \\
\text { learning environment in } \\
\text { Facebook helped develop cross- } \\
\text { cultural academic relationships } \\
\text { with students." }\end{array}$ & 6.2 & $89 \%$ & 6.4 & $96 \%$ & 6.3 & $92 \%$ \\
\hline $\begin{array}{l}\text { "Upon reflection, the online } \\
\text { learning environment in } \\
\text { Facebook helped develop cross- } \\
\text { cultural social relationships with } \\
\text { students." }\end{array}$ & 5.4 & $79 \%$ & 6.0 & $82 \%$ & 5.7 & $80 \%$ \\
\hline
\end{tabular}

Open-ended responses from this section of the survey were enlightening on the overall learning experience as well:

I don't think I would have made as many friends as quickly as I did without this course. It was really refreshing to use Facebook as a learning tool, because it was very popular with students, but also very effective for the course. (Local student, 2010 cohort)

To be able to discuss design and student work was great. It helped us learn more about design and learn more about our fellow students. I couldn't do this in class at first, but now I am confident to discuss during classes. (International student, 2009 cohort)

Yeah, overall it was great for forming connections. It got everyone talking from day one. Not bad for a first year class. (Local student, 2008 cohort) 


\section{Recommendations for using Facebook as an online learning environment}

The four year study in Imaging Our World provided much insight into the use of Facebook as a learning environment in first year design education. The 2008 experience showed that the virtual classroom hosted by Facebook provided a platform for students to generate preliminary academic and social interactions with peers in first year university, while meeting the diverse learning needs and attitudes of Generation-Y. The 2009 experience outlined a blended learning environment helped transform emergent online connections into meaningful relationships by supporting virtual communication with face-to-face interaction in the classroom. A shift in focus from stand-alone content galleries to work-in-progress galleries in 2010 revealed that the virtual environment in Facebook enabled students to produce strong academic results, by submitting preliminary design work throughout the semester and receiving constant feedback from a range of sources. While the success of the 2011 collaborative design studio was limited due to the separate host sites of the two Australian universities, the interaction between Adelaide and Singaporean cohorts indicated that Facebook has the potential to host national and international design classrooms, allowing students from around the world to connect with their global peers, learn about new fields of design, and improve their own work via feedback from an ever-growing number of sources.

Based on the four year study in Imaging Our World, the following eleven recommendations have been established for using Facebook as an online learning environment in first year education:

Be aware of privacy settings

It is crucial to ensure every student is aware of, and familiar with, all privacy settings associated with both their personal profile page, and their submissions to the established learning environment, in Facebook. Students should possess a strong knowledge of how to manage their friends into lists, and if necessary, set up a secondary profile specifically for academic use.

The course coordinator must also ensure that all students are aware of all the information they are potentially sharing with their peers and staff. Facebook allows users to control all of their information, and also how this information is shared. Users can manage the privacy of their status updates, photos and information using the 'inline audience selector' - this can be done both before and after sharing information. Users can also limit the audience for posts they shared with friends of friends or the general public.

Outline clear guidelines for participation within the online learning environment

The course coordinator should ensure students are aware of the rules and regulations that govern the learning environment, be it the physical or virtual classroom. The same rules should apply to both learning environments - the use of Facebook as a learning environment does not mean students, or staff, have the right to act or participate in an inappropriate way.

Clarify why Facebook is being used within the educational context of the course, and in particular, establish clear guidelines and boundaries regarding participation in activities.

Be aware of the information being shared with students

Staff should be aware of all the information they are potentially sharing with their students. It is recommended that staff either ensure their personal profile on Facebook is suitable to share, or they create a separate professional profile to use within the learning environment.

Staff should maintain a professional attitude when utilising this online environment, just as they should when teaching in a physical classroom. The use of social media within education does not mean the role or attitudes of the teacher need to change. It is simply another tool which can be used to enrich the learning environment.

It is also important to note that for a teacher and student to co-exist within a community in Facebook they do not need to be Facebook friends. Both parties can still communicate via the group or page of which they are members; they can both share information; photos and videos; and comment on each other's submissions. Furthermore both parties can still communicate via private emails (Facebook messages) should the need arise. 
Actively participate in Facebook

Staff should lead by example by actively participating within the learning environment. Staff should provide content, comments and critiques to student work; use the wall feature to post information and links; use the discussions feature to initiate critical debate between the students; and use additional applications within Facebook, such as Quiz Monster, to enhance the learning environment.

While the online learning environment may have been established primarily to promote peer-to-peer interaction, the role, and constant participation, of the teacher is still important. Students regularly responded positively to the active participation of the staff involved in the four year study in Imaging Our World.

Link assessment to participation in the online learning environment

Ensure there is adequate assessment weighting linked to the bulk of the participation within the online learning environment in Facebook. This will help ensure constant participation from all students involved in the course, and encourage stronger submissions in the form of both content and peer critiques.

Understand that some students might not be digital savvy

The four year study in Imaging Our World indicated that the vast majority of students were already members of Facebook and had a strong working knowledge of the site and other online social networking tools. There were however some students who were less aware of such tools and required help setting up their profiles and understanding how to utilise the site. It is important to remember that not all students are digital natives and that an appropriate support system is available where required.

Promote non-assessable participation in the online learning environment

While it is important to link most of the participation in the online learning environment to assessment weighting, it is also beneficial to encourage student participation and content-creation to elements within the group that are not directly related to course assessment. This can include uploading applications to the group, starting discussions, topics or forums, and promoting upcoming institution-related social events. By encouraging this, students will feel more relaxed in the online learning environment and will be more likely to actively participate.

Promote a strong connection between all learning environments

Course coordinators should ensure there is a strong link between the online learning environment in Facebook and the physical classroom, be it a lecture, studio, tutorial or workshop. It is important to remember that a virtual connection is simply one part of establishing a meaningful relationship between peers.

The 2009 study in Imaging Our World (as well as the studies in 2010 and 2011) clearly showed that a combination of online and face-to-face interaction (blended learning) improves student learning outcomes and enriches the design studio experience, well beyond a purely virtual connection.

\section{Utilise all learning aspects of the online learning environment}

Course coordinators should use the Facebook group (or page) to show exemplars of student work throughout the semester. Providing examples of previous work is crucial for all students. Precedents influence professionals in every facet of life, particular in the design world, and the Facebook environment enables the creation of a simple, and accessible, online resource for students.

The group (or page) can also be used to showcase the course to potential future students, during information sessions and open days. Once again, an online gallery of student exemplars can be easily created and stored within the Facebook group (or page), and utilised by staff at any time.

Promote a strong connection between the Facebook assessment and major assessment

The 2010 and 2011 studies in Imaging Our World outlined many positives associated with linking the Facebook assessment to major projects or assignments within the course. By submitting work-in-progress throughout the semester, and receiving constant feedback and critiques from a range of sources, including peers and staff, students, including those from a non-design background, were able to improve their design knowledge and skills, and subsequently advance their academic progress. This is of additional benefit to first year students, who may come into a course with little or no design knowledge. 


\section{Connect with national and international partners}

Use the online learning environment to connect with national and international partners. The 2011 case study in Imaging Our World outlined many positives to emerge from the partnership between the University of Adelaide, Swinburne University and Nanyang Technological University. Students were able to connect with their global peers, learn about new fields of design, and improve their own work via feedback from an ever-growing number of sources.

Use a single host site for collaborative studios

In the 2011 study in Imaging Our World, the gap between Facebook and Flickr as host sites impacted on the success of the national collaboration between the University of Adelaide and Swinburne University. As such, it is recommended that a single host site is used for future collaborative projects or studios.

Interaction between Adelaide and Singaporean students was much stronger, maintained by the students' enthusiasm to learn about new forms of design, and supported by a shared host site.

\section{Outcomes from the four-year study}

This paper brings to the forefront significant issues for tertiary level educators, and within the research there a number of specific outcomes to be highlighted:

- The 2008 online learning environment in Facebook improved the international student experience by negating common triggers of loneliness and isolation. Students were immersed into a new and engaging network with their peers. They could participate in virtual discussions and critiques, and take time with their comments, rather than being put on the spot in the physical classroom. The students could also learn more about their peers, both fellow internationals and local students, and settle into their new environment.

- The online environment in 2008 promoted interaction between all peers, particularly cross-cultural interaction between local and international students, in the early weeks of the semester when it was apparent this would not happen in the physical classroom.

- The blended learning environment in 2009 transformed embryonic online connections into meaningful relationships by augmenting virtual communication with face-to-face interaction in the physical classroom.

- The blended learning environment also increased student participation and academic discussions in class. By providing an initial platform (a virtual discussion in Facebook), students were more comfortable participating in classes, and as a result, lectures were transformed from teacher-centred content delivery systems, to learner-centred collaborative classrooms.

- The establishment of the online learning environment in Facebook in 2008 saw an increase in academic performance within all students in the course Imaging Our World. Average grades for both local and international student groups went from a low to mid pass in 2006 and 2007, to a credit in 2008. This average of a credit was maintained from 2009 to 2011.

- Timely formative feedback assisted overall academic performance. A shift in focus from stand-alone content galleries to work-in-progress galleries in 2010 enabled students, including those from a non-design background, to produce strong results, by submitting preliminary design work throughout the semester and receiving constant feedback from a range of sources.

- In 2011 students were able to connect with their global peers, learn about new fields of design, and improve their own work via feedback from an ever-growing number of sources, via the collaborative design studio hosted through Facebook and Flickr. 
Within the course Imaging Our World, the online environment in Facebook improved the first year experience by providing students with a platform to establish connections with their peers. The virtual environment negated common first year communicative pitfalls, and enabled interaction that might not have otherwise occurred. Between 2008 and 2011, relationships, both academic and social, were forged between peers; these relationships provided support for students as they adjusted to university life, and led to a sense of belonging in the learning community.

The success of the four-year study has led to new international connections being formed within Facebook. In 2012 a collaborative animation forum was established in Facebook, allowing students from the University of South Australia in Australia, Nanyang Technological University in Singapore, and Penn State University in the United States to connect with their global peers. This new collaboration will be reported on in future publications.

\section{References}

Bruns, A. (2008). Blogs, wikipedia, second life, and beyond: From production to produsage. New York: Peter Lang.

Bryant, T. (2006). Social software in academia. EDUCAUSE Quarterly, 29(2), 61-64.

Cluett, L. (2010, January). Online social networking for outreach, engagement and community: The UWA Students' Facebook page. In Educating for sustainability. Proceedings of the 19th Annual Teaching Learning Forum. Perth: Edith Cowan University. Retrieved from http://otl.curtin.edu.au/tlf/tlf2010/refereed/cluett.html

Duffy, P. (2011). Facebook or Faceblock. In C. McLoughlin \& M. Lee (Eds.), Web 2.0 based e-learning: applying social informatics for tertiary teaching (pp. 284-300).

Fischer, G. (2001). Communities of interest: learning through the interaction of multiple knowledge systems. Paper presented at the $24^{\text {th }}$ Information systems research seminar. Bergen, Norway. Retrieved from http://home.himolde.no/ molka/in765/Communities-of-Interest.pdf

Gee, J. P. (2004). Situated language and learning: A critique of traditional schooling. New York: Routledge.

Irwin, C., Ball, L., Desbrow, B., \& Leveritt, M. (2012). Students' perceptions of using Facebook as an interactive learning resource at university. Australasian Journal of Educational Technology, 28(7), 1221-1232. Retrieved from http://www.ascilite.org.au/ajet/ajet28/irwin.html

Jenkins, H. (2006). Convergence culture: Where old and new media collide. New York: New York University Press.

Jenkins, H., Clinton, K., Purushotma, R., Robison, A. J., \& Weigel, M. (2007). Confronting the challenges of participatory culture: Media education for the 21st century. Chicago, IL: MacArthur Foundation. Retrieved from http://digitallearning.macfound.org/atf/cf/\%7B7E45C7E0-A3E0-4B89AC9C-E807E1B0AE4E\%7D/JENKINS_WHITE_PAPER.PDF

Keen, A. (2007). The cult of the amateur: How today's Internet is killing our culture. New York: Doubleday.

Kirkwood, K. (2010). The SNAP Platform: social networking for academic purposes. Campus-Wide Information Systems, 27(3), 118-126. doi:10.1108/10650741011054429

Krause, K. (2005). The changing student experience: Who's driving it and where is it going? Keynote paper presented at Student Experience Conference: Good Practice in Practice, Charles Sturt University, Wagga Wagga, NSW. Retrieved from http://www.griffith.edu.au/_data/assets/pdf_file/0003/39270/StudExpKeynote05.pdf 
Krause, K., Hartley, R., James, R., \& McInnis, C. (2005). The first year experience in Australian universities: Findings from a decade of national studies. Canberra: DEST. Retrieved from http://www.dest.gov.au/sectors/higher_education/publications_resources/profiles/first_year_experienc e.htm

Leadbeater, C. (2006). The ten habits of mass innovation. London, England: NESTA. Retrieved from http://www.nesta.org.uk/library/documents/final\%20proof.pdf

Leander, K. (2002). You won't be needing your laptops today: Wired bodies in the wireless classroom. In M. Knobel, \& C. Lankshear (Eds.), A New Literacies Sampler. Retrieved from http://www.soe.jcu.edu.au/sampler/

Lorenzo, G., Oblinger, D., \& Dziuban, C. (2006). How choice, co-creation, and culture are changing what it means to be net savvy. EDUCAUSE Quarterly, 30(1), 6-12. Retrieved from http://connect.educause.edu/Library/EDUCAUSE+Quarterly/HowChoiceCoCreationandCul/40008

McCarthy, J. (2009). Utilising Facebook: immersing Generation-Y students into first year university. Journal of the Education Research Group of Adelaide, 1(2), 39-49.

McCarthy, J. (2010). Blended learning environments: Using social networking sites to enhance the first year experience. Australasian Journal of Educational Technology, 26(6), 729-740. Retrieved from http://www.ascilite.org.au/ajet/ajet26/mccarthy.html

McCarthy, J. (2012). International design collaboration and mentoring for tertiary students through Facebook. Australasian Journal of Educational Technology, 28(5), 755-775. Retrieved from http://www.ascilite.org.au/ajet/ajet28/mccarthy.html

McLoughlin, C., \& Lee, M. J. W. (2008). The three P's of pedagogy for the networked society: Personalization, participation, and productivity. International Journal of Teaching and Learning in Higher Education, 20(1), 10-27. Retrieved from http://www.isetl.org/ijtlhe/pdf/IJTLHE395.pdf

New London Group. (2000). A pedagogy of multiliteracies: Designing social futures. In B. Cope \& M. Kalantzis (Eds.), Multiliteracies: Literacy Learning and the Design of Social Futures (pp. 9-38). London: Routledge..

Nikunen, K. (2011). Participatory culture in multicultural societies: new challenges for audience research in Finland. Retrieved from Overview of European audience research: Research report from the COST Action (IS0906 Transforming Audiences, Transforming Societies, pp. 65-67). http://medienorge.uib.no/files/Eksterne_pub/Overview_of_European_Audience_Research.pdf

Palloff, R., \& Pratt, K. (2007). Building online learning communities: effective strategies for the virtual classroom. San Francisco: Jossey-Bass.

Punie, Y., \& Cabrera, M. (2006). The future of ICT and learning in the knowledge society. Luxembourg: European Communities. Retrieved from http://ftp.jrc.es/EURdoc/eur22218en.pdf

Rambe, P. (2012). Critical discourse analysis of collaborative engagement in Facebook postings. Australasian Journal of Educational Technology, 28(2), 295-314. Retrieved from http://www.ascilite.org.au/ajet/ajet28/rambe.html

Richardson, W. (2006). Blogs, wikis, podcasts, and other powerful tools for classrooms. Thousand Oaks, CA: Sage.

Robbie, D., \& Zeeng, L. (2008). Engaging student social networks to motivate learning: Capturing, analysing and critiquing visual image. The International Journal of Learning, 15(3), 153-160.

Sawir, E., Marginson, S., Deumert, A., Nyland, C., \& Ramia, G. (2008). Loneliness and international students: An Australian study. Journal of Studies in International Education, 12(2), 148-180. 
Staley, D. (2009). Managing the platform: higher education and the logic of Wikinomics. EDUCAUSE Review, 44(1), 36-47.

Stutzman, F. (2007). The vibrancy of online social space. Retrieved from http://fredstutzman.com/papers/MG2008_Stutzman.pdf

Tyson, W. (2010). Pitch Perfect. Virginia: Stylus Publishing.

Wenger, E. (1998). Communities of practice: Learning, meaning, and identity. Cambridge UK: Cambridge University Press.

Willis, P. (2003). Foot soldiers of modernity: The dialectics of cultural consumption and the 21st-century school. Harvard Educational Review, 73(3), 390-415.

Corresponding author: Josh McCarthy, josh.mccarthy@unisa.edu.au

Australasian Journal of Educational Technology (C) 2013.

Please cite as: McCarthy, J., (2013). Learning in Facebook: First year tertiary student reflections from 2008 to 2011. Australasian Journal of Educational Technology, 29(3), 337-356. 